\title{
EXPERIMENTAL STUDY ON SURFACE INTEGRITY IN END MILLING OF HASTELLOY C-2000 SUPERALLOY
}

\author{
N. H. $\operatorname{Razak}^{1}$, M. M. $\operatorname{Rahman}^{1 *}$ and K. Kadirgama ${ }^{1}$ \\ ${ }^{1}$ Faculty of Mechanical Engineering, Universiti Malaysia Pahang, \\ 26600, Pekan, Malaysia \\ *Email:mustafizur@ump.edu.my \\ Phone: +6094246239; Fax: +609424622
}

\begin{abstract}
This paper presents an experimental study of surface integrity in end milling of Hastelloy C-2000. The experiment was carried out using two different cutting inserts under wet conditions - namely physical vapor deposition coated carbide with TiAlN and uncoated carbide. Design of experiment was implemented with a Box-Behnken design. The surface integrity of the workpiece was analyzed through scanning electron microscopy (SEM) and chemical element changes were inspected by an energy dispersive X-ray (EDX) test. The surface integrity of Hastelloy C-2000 was better when machining with coated carbide compared to uncoated carbide cutting inserts, mainly because the coating layer of coated carbide acted as a protecting layer to the cutting tool insert. Surface defects such as feed marks, surface tearing, plucking, cracking and adhered chips were found during the machining process. The chemical element changes happened due to the adhesion and diffusion mechanisms which were identified using SEM and EDX.
\end{abstract}

Keywords: Nickel based superalloy; coated carbide; end mill; uncoated carbide; adhesion wear; diffusion wear.

\section{INTRODUCTION}

Hastelloy C-2000 is a nickel-chromium-molybdenum (Ni-Cr-Mo) C-type alloy which is used in the aerospace, marine, food processing, and chemical process industries (Khan, Rahman, Kadirgama, Maleque, \& Ishak, 2011; Razak, Rahman, \& Kadirgama, 2012a; Yusoff, Mohamed Suffian, \& Taib, 2011). The alloy can contain carbides and abrasive particles that can create high tool wear. According to Shokrani, Dhokia, and Newman (2012) difficulties as well as high costs can be expected in machining of these alloys because it was designed to retain its strength at elevated temperatures. Thus, great efforts have been made to find an economical method of machining these alloys to enhance their performance. The condition of a machined surface may be innate or else it requires surface integrity analysis of the mechanical, metallurgical, chemical and topological state of the surface. Changes in corrosion resistance, hardness variation, surface roughness, residual stress, etc. are then used to measure these states. The surface integrity is thus given great attention during machining. It is reported that thermal and mechanical cycling, microstructural transformations, and mechanical and thermal deformations during machining processes are caused by these impacts (Axinte \& Dewes, 2002; Kumar \& Singh, 2010; Singh \& Singh, 2011). In any case where the fatigue life of a machined part is deemed central, the smoothest possible surface is 
important (Novovic, Dewes, Aspinwall, Voice, \& Bowen, 2004). The greater strength of nickel-based alloys is due to elevated temperature, high ductility and a high tendency to work hardening. Thus, heat treatment strengthens the superalloys because of their sensitivity to microstructure change (Dudzinski et al., 2004). Another factor that can be essentially critical to the machined surfaces is the shape of the cutting tool. By feeding in a machine with a round-shaped cutting insert, the surface finish can be rectified with minimum surface damage. The hardness of the surface layer and the machined surfaces is inversely proportional when exposed to extended machining. The reason for this is the high flank wear. As a result, the component forces and cutting temperature increase because of the higher contact area and relative motion between the flank area of the tool nose region and the freshly machined surface of the workpiece (Habeeb, Abou-ElHossein, Mohammad, \& Kadirgama, 2008; Habeeb et al., 2010). The residual stresses, chemical change between the workpiece and tool materials, micro cracking, tears, plastic deformation, metallurgical transformations and changes in hardness of the surface layer are declared as the foremost changes in the machined surface layer. This paper presents the surface integrity of end milled characterization of Hastelloy C-2000.

\section{METHODS AND MATERIALS}

\section{Design of Experiments}

Design of experiments (DOE) is used to reduce the number of experiments and time consumption. The study uses the Box-Behnken design because it has fewer design points and is less expensive to run than central composite designs with the same number of factors. The Box-Behnken design was used to optimize the experiment to judge the effects of important parameters by using the response surface method (Abou-El-Hossein, Kadirgama, Hamdi, \& Benyounis, 2007; Boersma, 2011; Rahman, Khan, Kadirgama, Noor, \& Bakar, 2010a, 2010b; Zhao, Wu, \& Wang, 2006). Three levels of cutting parameters were selected to investigate the machinability of this alloy, as shown in Table 1. The parameter inputs were recommended by Kadirgama et al. (2009) Table 2 shows parameter settings in the DOE.

Table 1. Machining parameters and their levels

\begin{tabular}{lccc}
\hline \multicolumn{1}{c}{ Process } & \multicolumn{3}{c}{ Level } \\
\cline { 2 - 4 } parameters & -1 & 0 & 1 \\
\hline Feed rate (mm/tooth) & 0.1 & 0.15 & 0.2 \\
Axial depth $(\mathrm{mm})$ & 0.4 & 0.7 & 1 \\
Cutting speed $(\mathrm{mm} / \mathrm{min})$ & 15 & 23 & 31 \\
\hline
\end{tabular}

\section{Experimental Details}

The surfaces of Hastelloy C-2000 blocks of dimensions $46 \mathrm{~mm} \times 120 \mathrm{~mm} \times 20 \mathrm{~mm}$ were prepared using a moist cloth and sandpaper. As adhering dust makes the block very rough, it is very beneficial to clean it before further processing. The top surface was machined from the block. A dynamometer was attached to the slot and clamped to the block. A wet cutting condition was conducted to test the effectiveness of the HAAS TM-2 CNC milling machine. The machine was equipped with a $5.6 \mathrm{KW}$ motor drive, $400 \mathrm{rpm}$ spindle speed and $5.1 \mathrm{~m} / \mathrm{min}$ feed rate. Coated carbide (CTW 4615) and 
uncoated carbide (CTP 1235) were used in the cutting tool. For the 15 different experiments, a new set of cutting tools was used each time to get authentic data. Along with the dynamometer, a workpiece block was fastened onto the CNC milling table. On the other side, a CNC program was applied to cut the block into $120 \mathrm{~mm}$ lengths.

Table 2. DOE of Hastelloy C-2000

\begin{tabular}{cccc}
\hline Expt. no. & Feed rate $(\mathrm{mm} /$ tooth $)$ & Axial depth $(\mathrm{mm})$ & Cutting speed $(\mathrm{m} / \mathrm{min})$ \\
\hline 1 & 0.15 & 0.4 & 31 \\
2 & 0.15 & 1 & 15 \\
3 & 0.1 & 0.7 & 15 \\
4 & 0.2 & 1 & 23 \\
5 & 0.2 & 0.7 & 31 \\
6 & 0.15 & 0.7 & 23 \\
7 & 0.15 & 0.7 & 23 \\
8 & 0.2 & 0.7 & 15 \\
9 & 0.1 & 0.4 & 23 \\
10 & 0.15 & 1 & 31 \\
11 & 0.15 & 0.4 & 15 \\
12 & 0.1 & 0.7 & 31 \\
13 & 0.1 & 1 & 23 \\
14 & 0.15 & 0.7 & 23 \\
15 & 0.2 & 0.4 & 23 \\
\hline
\end{tabular}

A portable roughness tester (MarSurf PS) was used to measure the surface roughness of the block. A scanning electron microscope was used to analyze the integrity of the block surface. An advanced optical video computing system was used to evaluate the effectiveness of the cutting tool. The tool holder was removed from the panel of the testing machine during measurement operation. Flank wear was tested by using the tool to cut a $120 \mathrm{~mm}$ long block. After the first half, the tool wear at the face of the flank was measured to get an accurate result. The frequency of the tool wear depended upon the rate of growth when the wear. The actual life of the tool was calculated by the cutting-part's total cutting time to get a specific tool life. During the milling operation, a Kistler charge amplifier model 5070 and Kistler dynamometer model 1679A5 were used to measure the cutting force. These tools save the data of the critical forces into the computer for future analysis. At the end of this experiment, the chips were examined to determine the mechanism of their formation. The workpiece was removed from the clamp and then underwent a grinding and polishing process before examining the surface integrity of the workpiece using a scanning electron microscope. A mixture of epoxy and hardener was poured into a small container $30 \mathrm{~mm}$ in diameter. Before the next stage, the specimens were left to dry out and harden. Then a Cameo Platinum disk with a wheeler speed of $150 \mathrm{rpm}$ was used to grind the fixed workpiece. The polishing process starts with a Cameo Silver disk of 6 micron having a speed of $150 \mathrm{rpm}$, followed by a Cameo White FAS disk of 3 micron with a diamond mixture, along with a diamond mixture of 1 micron and red cloth plus a micro extender of speed $200 \mathrm{rpm}$. Before the last process of giving the workpiece an ultrasonic bath to get rid of the coolant and residue, polishing was done with colloidal silica of 0.05 micron along with an imperial cloth and water, having a wheeler speed of $150 \mathrm{rpm}$. The 
ultrasonic bath used was aqua regia-glycerol, an etching compound, and before this the specimen was cleaned with an ultrasonic cleaner. The chemical and physical properties of the Hastelloy C-2000 workpiece material are given in Table 3 and Table 4 respectively. The composition of the cutting insert is shown in Table 5.

Figure 1 shows the shape of the cutting insert. CTW 4615 is a coated carbide grade with TiAlN coating PVD with grade designation P35 M50. Titanium-aluminum nitride (TiA1N) is very effective in cutting stainless steels and aerospace alloys. The advantages of hard material layers consist in reduction of friction, heat, oxidation and diffusion. CTP 1235 is an uncoated carbide with grade designation K15. The following are the details of the tool geometry of the inserts when mounted on the tool holder: (a) special shape; (b) axial rake angle: $19.5^{\circ}$; (c) radial angle: $5^{\circ}$; and (d) sharp cutting edge. Fig. 1 shows the experimental setup and shape of the uncoated carbide inserts: (a) the workpiece at the CNC milling machine; (b) the shape of the cutting insert; and (c) SEM view of uncoated carbide before machining. Table 5 shows the composition of the cutting inserts.

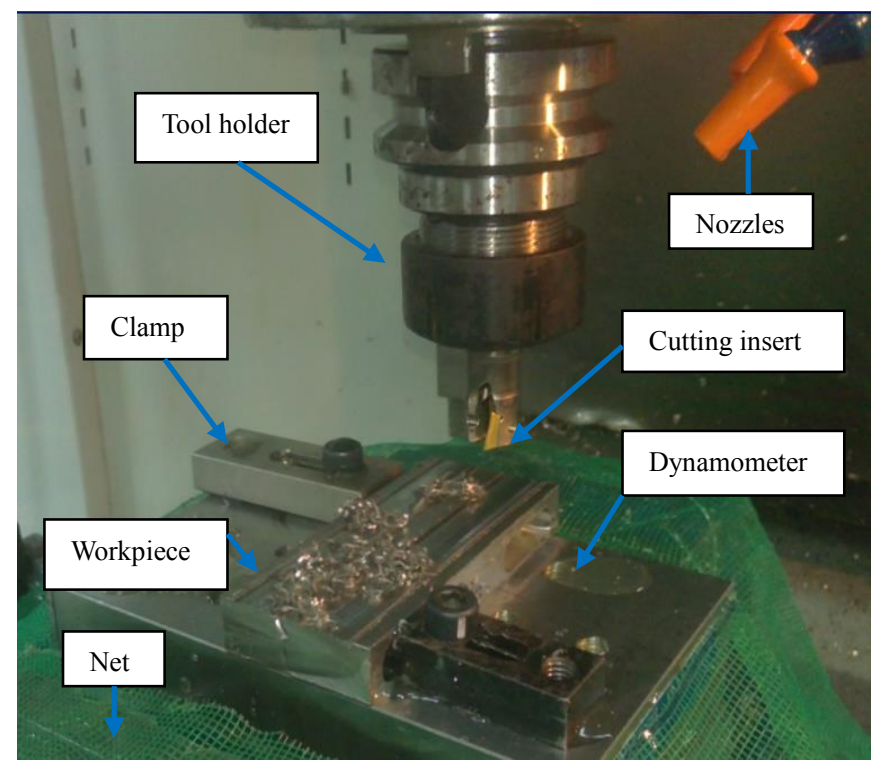

(a) Workpiece at CNC milling machine

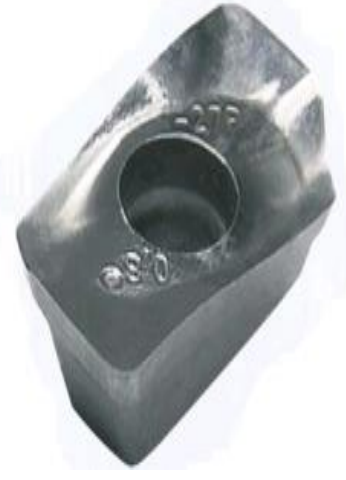

(b) Shape of cutting insert

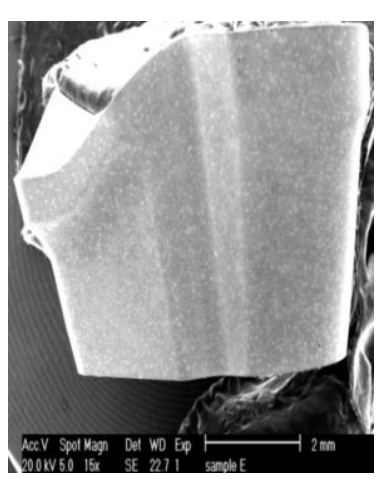

(c) SEM view

Figure 1. Experimental setup 
Table 3. Chemical composition (\%) of material (Hastelloy C-2000)

\begin{tabular}{ccccccccc}
\hline $\mathrm{Ni}$ & $\mathrm{Cr}$ & $\mathrm{Mo}$ & $\mathrm{Fe}$ & $\mathrm{Cu}$ & $\mathrm{Al}$ & $\mathrm{Mn}$ & $\mathrm{Si}$ & $\mathrm{C}$ \\
\hline $\mathrm{BAL}$ & 23 & 16 & 3 & 1.60 & 0.50 & 0.50 & 0.08 & 0.01 \\
\hline
\end{tabular}

Table 4. Physical properties of workpiece material (Hastelloy C-2000 at room temperature)

\begin{tabular}{lc}
\hline \multicolumn{1}{c}{ Parameters and unit } & Value \\
\hline Density $\left(\mathrm{g} / \mathrm{cm}^{3}\right)$ & 8.5 \\
Thermal conductivity $\left(\mathrm{W} / \mathrm{m}^{\circ} \mathrm{C}\right)$ & 9.1 \\
Mean coefficient of thermal expansion $\left(\mu \mathrm{m} / \mathrm{m}^{\circ} \mathrm{C}\right)$ & 12.4 \\
Thermal diffusivity $\left(\mathrm{cm}^{2} / \mathrm{s}\right)$ & 0.025 \\
Specific heat $\left(\mathrm{J} / \mathrm{kg}^{\circ} \mathrm{C}\right)$ & 428 \\
Modulus of elasticity & 223 \\
\hline
\end{tabular}

Table 5. Composition of the cutting inserts

\begin{tabular}{lccc}
\hline \multicolumn{1}{c}{ Code name } & Composition & Coating & Grain size \\
\hline CTW 4615 & $6 \%$ Co, $4 \%$ carbide,90\% WC & PVD-TiA1N,TiN & $1 \mu \mathrm{m}$ \\
CTP 1235 & $6 \%$ Co, $94 \%$ WC & - & $4 \mu \mathrm{m}$ \\
\hline
\end{tabular}

\section{RESULTS AND DISCUSSION}

Micrographs of coated and uncoated carbide inserts can be observed in Figure 2, which shows the images from the scanning electron microscope (SEM). A feed rate of 0.2 $\mathrm{mm} /$ tooth, axial depth $0.7 \mathrm{~mm}$ and cutting speed $15 \mathrm{~m} / \mathrm{min}$ was used for the images taken and a surface defect was found due to the low cutting speed. During the machining of the workpiece of the coated carbide cutting insert, several kinds of surface defects occurred. Of these, surface flaws, feed marks and chip redeposition were the most common kinds of defects, as shown in Figure 2(a). The severity of a feed mark can be changed by optimizing the feed rate or varying it in order to carry out an effective machining process (Dubey, Shan, \& Jain, 2009). Furthermore, plucking of particles from the surface and their redeposition to the surface create two different defects. The particles have the ability to cause a tearing and dragging effect on the surface of the next pass. In the case of uncoated carbide, the same kind of surface plucking and tearing would take place. Uncoated carbide has a very different surface texture from coated carbide, mainly because the coating layer helps to make the tool harder and tougher with a good surface finish. The residual stress which is present on the machine surface is improved, along with reducing the cutting temperature and enhancing the machine surface with the help of the coating layer (Outeiro, Pina, M'Saoubi, Pusavec, \& Jawahir, 2008). It was observed that the compressive stresses increase with increase of the thermal softening of the material and such surface flaws clear out of the machined surface, enabling the near-surface area of the workpiece to reconstruct itself easily (Kadirgama, Abou-El-Hossein, Mohammad, Noor, \& Sapuan, 2008).

Prolonged machining tends to increase the hardness of the surface layer and also causes the surface finish of the machined workpiece to deteriorate because the contact area and motion that exists between the tool, flank area and workpiece machine surface is increased, hence causing surface defects, increased component cutting forces and 
temperature and flank wear. With the presence of nickel-based alloys, many issues arise since the cutting parameters affect the defects to some extent. To avoid these problems, optimization of the cutting condition is essential. The machining processes have been observed to have many defects in the surface, specifically in the micron precisions. It is not feasible to entirely remove the cutting parameters or even adjust them to any extent. There are carbide particles in the structure of nickel-based work piece materials along with coating inserts material with carbide particles. Detachment of the carbide particles from the machine surface or tool inserts occurs when the workpiece is machined or when they are stuck on the workpiece surface. This process is referred to as carbide cracking and may cause an increase in the level of stress when the cutting takes place due to plucking in the surface cavities (Kadirgama, Abou-El-Hossein, Noor, Sharma, \& Mohammad, 2011).

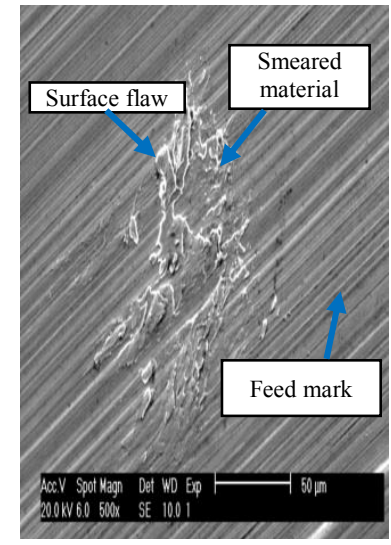

(a) Coated carbide

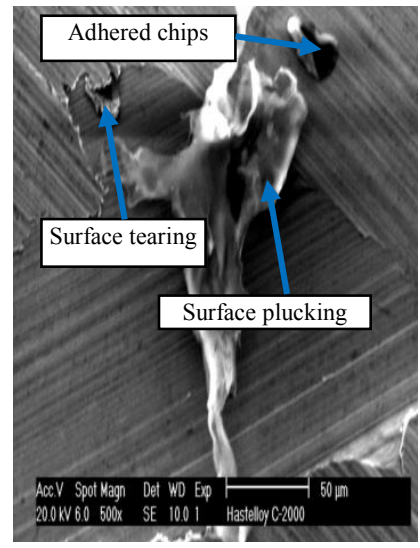

(b) Uncoated carbide

Figure 2. SEM view of Hastelloy C-2000 texture at 500x

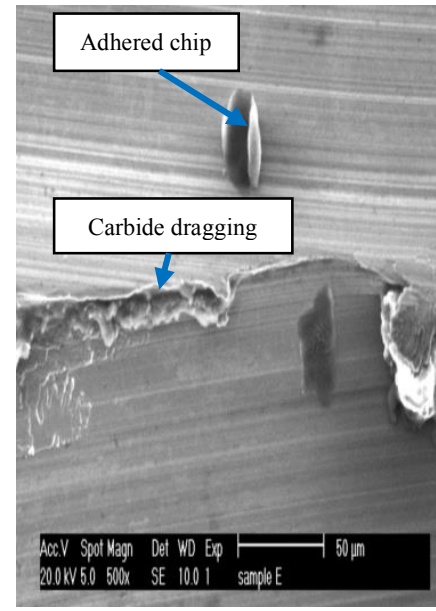

(a) Magnification, 500x

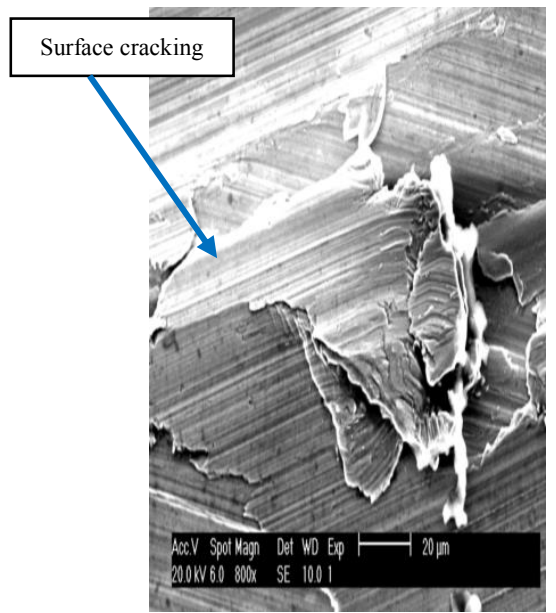

(b) Magnification, $800 \mathrm{x}$

Figure 3. SEM view of experiment no. 3 with two different magnifications for uncoated carbide insert.

Figure 3 shows the carbide cracking formation. Residual cavities and cracks occur in the machine surface, which may cause several issues in terms of the micro- 
scale surface integrity. The chemical composition of the material when machining of the coated and uncoated carbide tool inserts takes place is shown in Table 4. Cobalt has been formed in the EDX test when checking the texture of the machined surface, hence proving that an adhesion mechanism does take place, as shown in Figure 4(Kadirgama et al., 2011). This cobalt (Co) is a new element of the Hastelloy C-2000 which is present due to the high temperature of machining and the chemical change that takes place between the cutting tool insert and the workpiece.

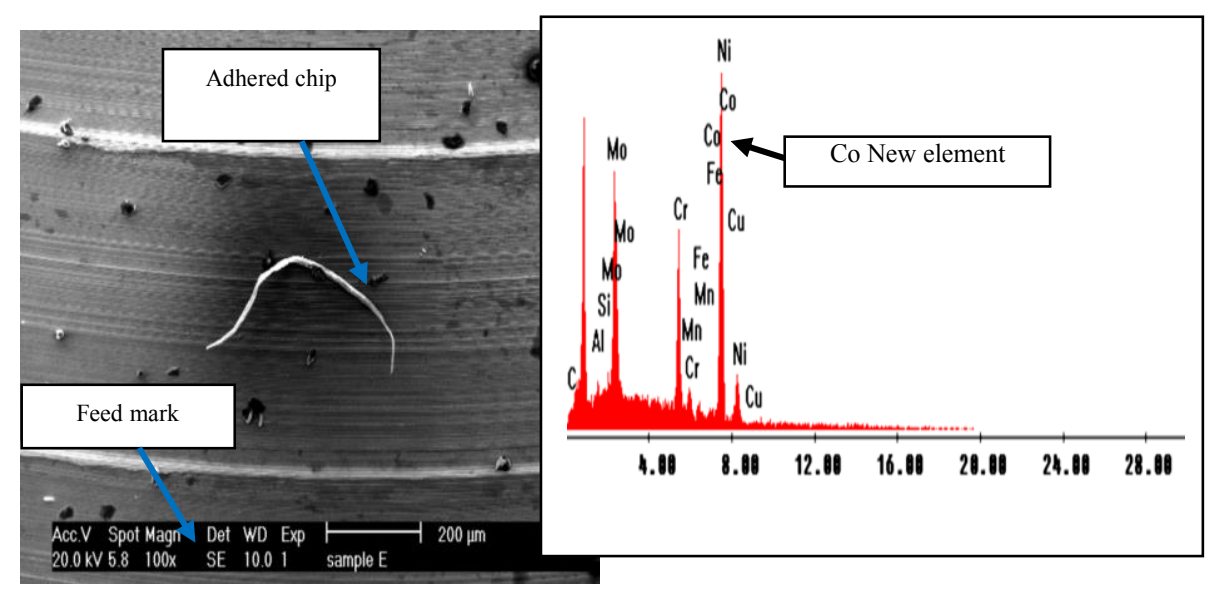

Figure 4. Adhesion and diffusion based on EDX result at magnification 100x for coated carbide inserts

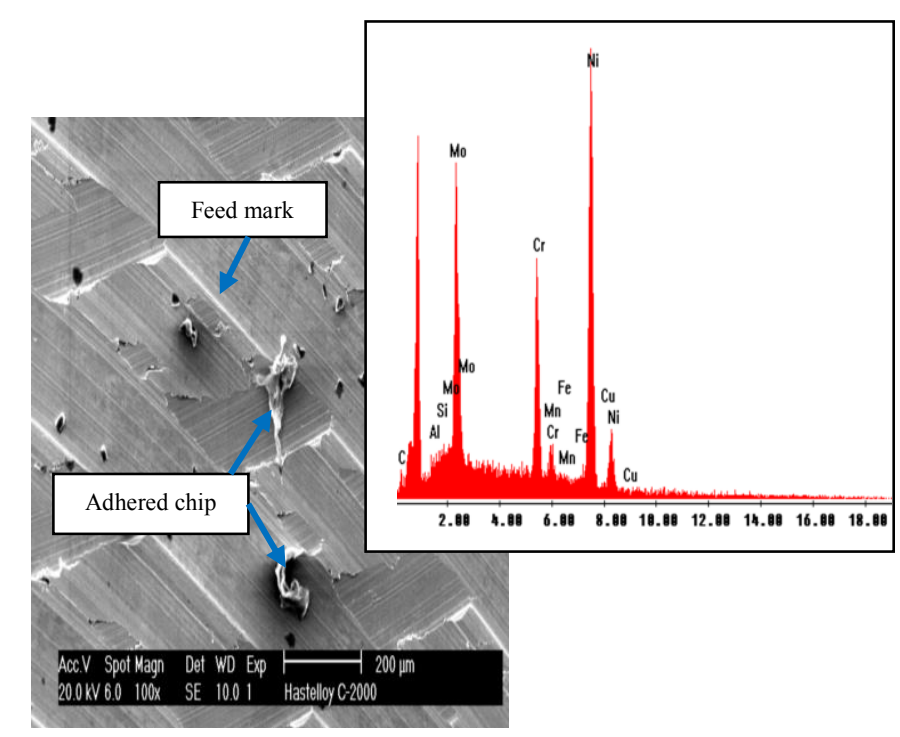

Figure 5. Diffusion based on EDX result at magnification 100x for uncoated carbide insert

The formation of cobalt occurred due to an adhesive mechanism during machining, where the coated carbide itself contains the component of cobalt. The rake face was protected with the help of the adhering element $(\mathrm{Co})$ as it became a stable built-up edge (Itakura et al., 1999). Diffusion took place where there was a vast increase or decrease in the elements of carbon $(\mathrm{C})$, aluminum $(\mathrm{Al})$ and molybdenum (Mo). Due to this mechanism, the atoms present in the metallic crystal lattice change 
from a higher atomic concentration to a lower concentration level. The case of diffusion also occurs when applying uncoated carbide, although without the adhesion formation found with the coated carbide, as shown in Figure 5. Diffusion takes place during the cutting condition of a feed rate of $0.2 \mathrm{~mm} /$ tooth, axial depth $1.0 \mathrm{~mm}$ and cutting speed $23 \mathrm{~m} / \mathrm{min}$. Here, there is a decrease in the composition of chromium $(\mathrm{Cr})$, manganese $(\mathrm{Mn})$, copper $(\mathrm{Cu})$, iron $(\mathrm{Fe})$ and nickel $(\mathrm{Ni})$ and an increase is observed in molybdenum (Mo), aluminum (Al), silicon ( $\mathrm{Si}$ ), and carbon. The changes of chemical composition when machining Hastelloy C-2000 with coated and uncoated carbide inserts can be seen in Table 6.

Table 6. Chemical composition (\%) of material (Hastelloy C-2000) before and after machining for coated and uncoated carbide inserts

\begin{tabular}{lccc}
\hline Components & Before machining & \multicolumn{2}{c}{ After machining } \\
\cline { 2 - 4 } & & Coated carbide & Uncoated carbide \\
\hline $\mathrm{Ni}$ & 55.310 & 54.00 & 54.22 \\
$\mathrm{Cr}$ & 23.000 & 12.83 & 15.28 \\
$\mathrm{Mo}$ & 16.000 & 24.53 & 24.84 \\
$\mathrm{Fe}$ & 3.000 & 1.05 & 0.45 \\
$\mathrm{Cu}$ & 1.600 & 2.16 & 1.25 \\
$\mathrm{Al}$ & 0.500 & 1.20 & 0.58 \\
$\mathrm{Mn}$ & 0.500 & 0.57 & 0.29 \\
$\mathrm{Si}$ & 0.008 & 0.76 & 0.71 \\
$\mathrm{C}$ & 0.010 & 1.89 & 2.38 \\
$\mathrm{Co}$ & - & 1.01 & - \\
\hline
\end{tabular}

\section{CONCLUSIONS}

Uncoated carbide has a very different surface texture from coated carbide, mainly because the coating layer helps make the tool harder and tougher with a better surface finish. The residual stress on the machine surface is improved, along with reducing the cutting temperature and enhancing the machine surface with the help of the coating layer. Prolonged machining tends to increase the hardness of the surface layer and also causes the surface finish of the machined workpiece to deteriorate. The contact area and motion that exists between the tool, flank area and workpiece machine surface is increased, hence causing surface defects, and increased component cutting forces and temperature and flank wear. There are carbide particles in the structure of nickel-based workpiece materials along with coating inserts material with carbide particles.

\section{ACKNOWLEDGMENTS}

The authors would like to acknowledge the support of Universiti Malaysia Pahang for funding under Graduate Research Scheme (Project No. RDU110110).

\section{REFERENCES}

Abou-El-Hossein, K. A., Kadirgama, K., Hamdi, M., \& Benyounis, K. Y. (2007). Prediction of cutting force in end-milling operation of modified aisi p20 tool steel. Journal of Materials Processing Technology, 182(1-3), 241-247. 
Axinte, D. A., \& Dewes, R. C. (2002). Surface integrity of hot work tool steel after high speed milling - experimental data and empirical models. Journal of Materials Processing Technology, 127, 325-332.

Boersma, B. J. (2011). A 6th order staggered compact finite difference method for the incompressible navier-stokes and scalar transport equations. Journal of Computational Physics, 230(12), 4940-4954.

Dubey, A. K., Shan, H. S., \& Jain, N. K. (2009). Precision microfinishing by electrochemical honing. International Journal of Manufacturing Technology and Management, 17(4), 364-372.

Dudzinski, D., Devillez, A., Moufki, A., Larrouquere, D., Zerrouki, V., \& Vigneau, J. (2004). A review of developments towards dry and high speed machining of inconel 718 alloy. International Journal of Machine Tools and Manufacture, 44, 439-456.

Habeeb, H. H., Abou-El-Hossein, K. A., Mohammad, B., \& Kadirgama, K. (2008). Effect of tool holder geometry and cutting condition when milling nickel-based alloy 242. Journal of Materials Processing Technology, 201(1-3), 483-485.

Habeeb, H. H., Kadirgama, K., Noor, M. M., Rahman, M. M., Mohammad, B., Bakar, R. A., \& Abouel Hossein, K. A. (2010). Machining of nickel alloy 242 with cubic boron nitride tools. Journal of Applied Sciences, 10, 2322-2327.

Itakura, K., Kuroda, M., Omokawa, H., Itani, H., Yamamoto, K., \& Ariura, Y. (1999). Wear mechanism of coated cemented carbide tool in cutting of inconel 718 super-heat-resisting alloy. International Journal of the Japan Society for Precision Engineering, 33, 326-332.

Kadirgama, K., Abou-El-Hossein, K. A., Mohammad, B., Noor, M. M., \& Sapuan, S. M. (2008). Prediction of tool life by statistic method in end-milling operation. Scientific Research and Essays, 3(5), 180-186.

Kadirgama, K., Abou-El-Hossein, K. A., Noor, M. M., Sharma, K. V., \& Mohammad, B. (2011). Tool life and wear mechanism when machining hastelloy C-22HS. Wear, 270(3-4), 258-268.

Kadirgama, K., Noor, M. M., Rahman, M. M., Rejab, M. R. M., Haron, C. H. C., \& Abou-El-Hossein, K. A. (2009). Surface roughness prediction model of 6061-t6 aluminium alloy machining using statistical method. European Journal of Scientific Research, 25(2), 250-256.

Khan, M. A. R., Rahman, M. M., Kadirgama, K., Maleque, M. A., \& Ishak, M. (2011). Prediction of surface roughness of Ti-6Al-4V in electrical discharge machining: A regression model. Journal of Mechanical Engineering and Sciences, 1, 16-24.

Kumar, S., \& Singh, R. (2010). Investigation of surface properties in manganese powder mixed electrical discharge machining of OHNS and D2 die steels. International Journal of Automotive and Mechanical Engineering, 2, 181-199.

Novovic, D., Dewes, R. C., Aspinwall, D. K., Voice, W., \& Bowen, P. (2004). The effect of machined topography and integrity on fatigue life. International Journal of Machine Tools and Manufacture, 44, 125-134.

Outeiro, J. C., Pina, J. C., M'Saoubi, R., Pusavec, F., \& Jawahir, I. S. (2008). Analysis of residual stresses induced by dry turning of difficult-to-machine materials. CIRP Annals-Manufacturing Technology, 57, 77-80.

Rahman, M. M., Khan, M. A. R., Kadirgama, K., Noor, M. M., \& Bakar, R. A. (2010a). Mathematical modeling of material removal rate for Ti-5Al-2.5Sn through edm process: A surface response method. Advances in Control, Chemical Engineering, Civil Engineering and Mechanical Engineering, 34-37 
Rahman, M. M., Khan, M. A. R., Kadirgama, K., Noor, M. M., \& Bakar, R. A. (2010b). Modeling of material removal on machining of ti-6al-4v through edm using copper tungsten electrode and positive polarity. World Academy of Science, Engineering and Technology, 71, 576-581.

Razak, N. H., Rahman, M. M., \& Kadirgama, K. (2012a). Investigation of machined surface in end-milling operation of hastelloy c-2000 using coated-carbide insert. Advanced Science Letters, 13, 300-305.

Shokrani, A., Dhokia, V., \& Newman, S. T. (2012). Environmentally conscious machining of difficult-to-machine materials with regard to cutting fluids. International Journal of Machine Tools and Manufacture, 57, 83-101.

Singh, R., \& Singh, B. (2011). Comparison of cryo-treatment effect on machining characteristics of titanium in electric discharge machining. International Journal of Automotive and Mechanical Engineering, 3, 239-248.

Yusoff, A. R., Mohamed Suffian, M. R. Z., \& Taib, M. Y. (2011). Literature review of optimization technique for chatter suppression in machining. Journal of Mechanical Engineering and Sciences, 1, 47-61.

Zhao, W., Wu, Z., \& Wang, D. (2006). Ozone direct oxidation kinetics of cationic red xgrl in aqueous solution. Journal of Hazardous Materials, 137, 1859-1865. 